\title{
Musik Dewa-Dewa Dalam Upacara Erau Pelas Benua di Guntung Kota Bontang Kalimantan Timur
}

\section{Yusuf Rizky N.C}

\begin{abstract}
Erau Pelas Benua Guntung is the ritual ceremony that held by Kutai Guntung society Bontang, East Borneo. Erau will be held for seven days. In this ceremony, the erau ritual can't be held if they are not doing the Pelas Benua. Pelas Benua is a ritual that sorrounds the four direction of the wind in Guntung as the form to clean up from the negative things. This ritual using Dewa-Dewa music as accompanist, the belian communicate to Dewa Semega, He is The God who control the universe. This research using qualitative method with ethnomusicology perspective. Music Dewa-Dewa is ritual music which is specially used in Pelas Benua procession. Music Dewa-Dewa is an ansamble which consist Klentangan, Gong, Gendang and Gimar instrument.

There are three function of Dewa-Dewa music in this ceremony, as communication, ritual function, and physical response. The form of presentation music Dewa-Dewa always can not be separated with form the context of Pelas Benua ceremony and presenting as the ansamble.
\end{abstract}

Keyword: Dewa-dewa Music, Erau Pelas Benua, Function of Music dewa-dewa, Guntung, form of presentation

\section{Abstrak}

Erau Pelas Benua Guntung adalah upacara ritual yang diadakan oleh masyarakat Kutai Guntung Bontang, Kalimantan Timur. Erau akan ditahan selama tujuh hari. Dalam upacara ini, ritual erau tidak dapat diadakan jika mereka tidak melakukan Pelas Benua. Pelas Benua adalah ritual yang mengelilingi keempat arah angin di Guntung sebagai bentuk untuk membersihkan dari hal-hal negatif. Ritual ini menggunakan musik Dewa-Dewa sebagai pengiring, belian berkomunikasi dengan Dewa Semega, Dia adalah Tuhan yang mengendalikan alam semesta.

Penelitian ini menggunakan metode kualitatif dengan perspektif etnomusikologi. Musik Dewa-Dewa adalah musik ritual yang khusus digunakan dalam prosesi Pelas Benua. Musik Dewa-Dewa adalah ansamble yang terdiri atas instrumen Klentangan, Gong, Gendang dan Gimar.

Ada tiga fungsi musik Dewa-Dewa dalam upacara ini, seperti komunikasi, fungsi ritual, dan respons fisik. Bentuk penyajian musik Dewa-Dewa selalu tidak dapat dipisahkan dengan bentuk konteks upacara Pelas Benua dan tampil sebagai ansamble.

Kata kunci: Musik Dewa-dewa, Erau Pelas Benua, Fungsi Musik dewa-dewa, Guntung, bentuk presentasi

\section{Pendahuluan}

\footnotetext{
${ }^{1}$ Mahasiswa Jurusan Etnomusikologi FSP Institut Seni Indonesia Yogyakarta
} 
Bontang merupakan salah satu kota yang berada di provinsi Kalimantan Timur. Kota Bontang merupakan salah satu kota industri yang ada di Indonesia, ada tiga perusahaan industri besar yang berdiri di kota Bontang yaitu perusahaan LNG Badak, Pupuk Kaltim, dan PT. Indominko. Masyarakat yang mendiami wilayah ini berasal dari etnis yang beragam seperti suku Dayak, Banjar, Jawa, Bugis, Kutai dan suku-suku pendatang yang lain dari seluruh Nusantara. Dengan beragamnya suku-suku yang ada di kota Bontang mengakibatkan kesenian yang beragam pula. Kota madya Bontang secara wilayah administratif memiliki tiga kecamatan dengan lima kelurahan, yang salah satunya ialah kelurahan Guntung. Guntung mempunyai arti yaitu genangan air yang tidak mempunyai hulu maupun hilir atau tempat yang subur tanahnya. Guntung sendiri saat ini merupakan wilayah kelurahan atau kampung yang mayoritas penduduknya adalah etnis Kutai. Warga yang tinggal di daerah Guntung merupakan keturunan dari kalangan keluarga kerajaan Kutai Kartanegara Ing Martadipura di Tenggarong yang kemudian bermigrasi ke wilayah Guntung sekitar tahun 1844 sampai 1948, Guntung sampai hari ini masih melaksanakan ritual upacara erau pelas benua karena masyarakat mempercayai adanya kekuatan diluar diri manusia salah satunya upacara erau pelas benua.

Erau Pelas Benua berasal dari bahasa Kutai yaitu, eroh, yang berarti ramai, riuh, ribut, suasana yang penuh suka cita. Upacara ini terdapat hampir di seluruh Provinsi Kalimantan Timur, dimana upacara ini merupakan sebuah ritual untuk mengucap rasa syukur kepada sang pencipta (Irawati, 2013: 24). Sedangkan pelas benua sendiri adalah persembahan kurban sebagai rasa syukur kepada Tuhan Yang Maha Esa atas rejeki yang diberikan. Ritual pelas вепиа ini ialah ritual turun menurun yang telah ada sejak masyarakat Kutai pindah ke daerah Guntung. pelas benua dilaksanakan satu hari sebelum kegiatan erau, upacara ini bertujuan untuk menghilangkan hal-hal negatif dan roh jahat di sekitar kota Bontang. Masyarakat Guntung mempercayai apabila tidak melakukan ritual pelas benиa ini akan terjadi malapetaka atau musibah. Erau pelas benua di Guntung dilakukan mulai tahun 1948 sampai sekarang (Wawancara Hamid, Bontang 23 Mei 2015). Pelaksanaan erau pelas benua Guntung inimerupakan gagasan dari masyarakat adat Odah Etam Kutai Guntung dan juga adanya dukungan dari pihak instansi pemerintahan Kota Bontang. Erau pelas benua Guntung berlangsung setiap tahun dan biasanya dilaksanakan pada bulan September. Ritual erau Pelas 
Вепиа memiliki tahapan-tahapan upacara yang harus di laksanakan salah satunya yaitu pelas benua.

Ritual pelas benua dilakukan dengan cara mengelilingi empat penjuru mata angin dan tempat-tempat vital di kota Bontang. Ritual pelas benиa ini dilakukan dengan berkeliling menggunakan mobil terbuka, mengelilingi kota Bontang dan ke empat penjuru mata angin yang kemudian direalisasikan dengan penyembelihan binatang yaitu kambing atau ayam. Darah dari binatang ini dipercik ke permukaan bumi,sebagai tanda syukur atas rejeki yang diberikan oleh Maha Pencipta atau Dewa Semega. Mereka beranggapan dengan percikan darah tersebut dapat membuang energi negatif dan bumi kembali netral sehingga masyarakat dapat terhindar dari perbuatan yang negatif atau juga hal-hal yang mengganggu (Wawancara Ahmad Bontang 27 September 2017).

Selama prosesi ritual pelas benua Guntung tidak bisa lepas dari iringan musik yaitu musik dewa-dewa. Dewa-dewa dalam kamus besar bahasa Indonesia sendiri ialah roh yang dianggap atau dipercayai sebagai manusia halus yang berkuasa atas alam dan manusia (Kamus Bahasa Indonesia, 2008: 349). Masyarakat Guntung sendiri mempunyai dewa yang paling atas yaitu Dewa Semega, merupakan penguasa atas dan bawah (langit dan bumi) oleh karena itu musik dewa-dewa ini ditujukan untuk alam kahyangan mikrokosmos agar tidak ada yang mengganggu di langit dan di bumi dan dapat bersinergi dengan manusia (Wawancara Ahmad Bontang 27 September 2017). Musik dewa-dewa disini memiliki pengertian sebagai nama ansambel yang mengiringi seluruh rangkaian ritual pelas benua. Dalam ansambel musik dewadewa terdapat beberapa instrumen yaitu gong, klentangan, dan gendang serta dipimpin oleh seorang dukun (belian) yang merupakan silsilah keturunan Kutai Kartanegara yang berasal dari suku Menamang. Upacara erau pelas benua yang masih dipertahankan ini merupakan sebagai cara suku kutai yang ada di Guntung menjaga tradisi Erau pelas benua dan juga prosesi pelas benua.

\section{Upacara Erau Pelas Benua}

Erau Pelas Benua yang biasanya dilaksanakan dengan sangat sederhana oleh penduduk Kutai di Guntung, merupakan upacara adat yang telah turun temurun dilaksanakan dan juga 
dirangkaikan pula dengan pagelaran seni tari dan musik serta olahraga tradisional dalam upaya memelihara, mengembangkan, melestarikan dan menggali adat istiadat seni dan budaya Kutai yang bertujuan agar terpeliharanya adat istiadat dan seni budaya yang adi luhung, dan semakin dicintainya budaya bangsa oleh masyarakat. Juga dalam upaya membina silaturahmi dan kerukunan dengan etnis-etnis pendatang lain yang ada di Kota Bontang maka dalan upacara ini diadakan pula pagelaran seni tari maupun seni musik dari berbagai etnis yang mencerminkan dan mewakili potensi seni budaya masyarakat yang hidup dan berkembang di Kota Bontang yang akan mempertebal wawasan budaya Nusantara.

Musik dewa-dewa merupakan salah satu kesenian tradisional yang masi ada didalam masyarakat Kutai Gutung sebagai sarana Upacara pelas benua. Musik dewa-dewa sendiri di kalangan masyarakat Kutai Guntung dikenal pula dengan sebutan musik dewa, namun lebih sering oleh masyarakat sekitar dengan sebutan musik dewa-dewa. Penyebutan ini karena musik yang ditampilkan ditujukan kepada para dewa dan roh-roh leluhur ataupun yang lain. Musik dewa-dewa ini merupakan musik ritual saat upacara pelas benua berlangsung, yang bertujuan memohon perlindungan dan meminta izin karna akan diadakannya erau esok harinya.

Musik dewa-dewa atau musik dewa berasal dari kata dewa yang artinya roh yang dianggap atau dipercayai sebagai manusia halus yang berkuasa atas alam dan manusia, orang atau sesuatu yang sangat dipuja (https://kbbi.web.id/dewa). Bagi sebagian masyarakat khususnya menganggap musik sebagai salah satu bagian atau sarana yang amat penting dalam proses upacara ritual, seperti pada: upacara kematian, perkawinan, pengobatan, pesta adat, dan lain sebagainya (Haryanto, 2015: 26). Sama halnya dengan musik dewa-dewa sebagai pengiring upacara pelas benua yang tidak boleh tidak ada karna merupakan sarana penting didalam upacara pelas benua.

Upacara adalah kegiatan keagamaan dan adat budaya yang terstruktur sebagai salah satu media untuk mendekatkan diri, memuja, menyembah, menghormat, memberi, memohon atau mengungkapkan rasa syukur kepada objek yang dituju(Senen, 2015: 18). Demikian pula dalam pelaksanaan upacara Pelas Benua yang mempunyai objek tujuan tertentu khususnya mempersembahkan kepada roh dan para dewa-dewa salah satunya dewa semega dan tentunya harus melalui syarat dan media simbolis tertentu yang dihadirkn dalam beberapa aspek. 
Aspek-aspek yang terdapat dalam upacara pelas benua tidak terlepas dari aspek musikal dan aspek non musikal.

Aspek non musikal merupakan segala unsur pendukung penyajian yang tidak berhubungan dengan bunyi (Senen,2015: 78). Aspek non musikal juga merupakan aspek di luar musik namun saling keterkaitan dengan musik itu sendiri, dalam artian lain yaitu berupa kontekstual musik saat dihadirkan. Aspek ini berkaitan dengan hal-hal yang terlihat dalam pertunjukan.

Pelas Benua dihadirkan sehari sebelum upacara erau dilaksanakan esok harinya. Upacara ini dimulai pada tanggal 17 September 2017 dan berahir pada tanggal 30 September 2017. Upacara Pelas Benua dilaksanakan sebelum Erau berlangsung yaitu pada siang sampai sore hari pukul 14:00 WITA menyembelih kambing dan persiapan Upacara Pelas Benua dan berkeliling pukul 16:00 WITA hingga selesai pukul 17:30 WITA. Pelas Вепиa berfungsi sebegai ritual meminta izin yang diiringi dengan musik dewa-dewa untuk memberi tahu roh yang tak kelihatan agar tidak mengganggu Upacara Erau esok harinya.

Musik dewa-dewa dilaksanakan pada saat Upacara Pelas Benua berlangsung, Musik dewa-dewa dimulai pukul 16:00 WITA. Lama pertunjuan sekitar 1 jam 30 menit dan menyusuaikan intruksi dari belian, karena musik dewa-dewa berfungsi sebagai musik pengiring upacara Pelas Benua. Tempat penyajian musik dewa-dewa ini adalah di rumah adat dan di sekitar kawasan vital Kota Bontang (Wawancara Juhar, Bontang 27 September 2017).

Salah satu aspek ritual non-musikal yang lain yaitu penikmat atau penonton. Penikmat kasat mata yaitu manusia yang terdiri dari para pelaku bunyi-bunyian, pelaksanaan upacara, peserta upacara, dan dan masyarakat sekitarnya. Sementara penikmat tidak kasat mata yaitu Tuhan, dewa, dan leluhur (Soedarsonono, 2002: 123). Upacara Pelas Benua memiliki aspek yang berarti bahwa penikmat dan penonton yang dipercaya berdimensi vertikal dan horizontal. Penikmat yang kasat mata adalah yang hadir secara nyata dan berperan dalam jalannya upacara. Sedangkan penikmat yang tidak kasat mata dalam upacara Pelas Benua ini adalah roh leluhur yang di percaya hadir yang telah diberitahu dalam upacara Pelas Benua.

Sesaji dipersembahkan kepada sesuatu yang dianggap gaib untuk menyatakan keseriusan. Sedangkan isinya merupakan bahan-bahan dari resep adat yang harus diikuti dan diturunkan dari masa ke masa ( Kasdini, 2012: 34). Sama halnya dengan kepercayaan 
masyakat Kutai Guntung yang masih menggunakan sarana persembahan berupa sesaji tersebut kepada roh leluhur dengan harapan mereka merasa senang, kenyang, dan tercukupi kebutuhannya, sehingga senantiasa memberikan kelancaran dalam upacar Erau esok harinya.

Transkripsi dalam penelitian ini menggunakan pendekatan prespektife

Yaitu menuliskan bagian-bagian yang menonjol dalam musik tidak harus mendetail. Penggunaan hasil transkripsi lagu/melodi menggunakan pendekatan notasi angka. Berikut adalah transkripsi musik dewa-dewa dalam upacara pelas benua.

$\begin{array}{ll}\text { Do } & =\text { Bes } \\ \text { Birama } & =4 / 4 \\ \text { Tempo } & =\text { Moderato }\end{array}$

\section{Musik Dewa Semega}

Musik dewa semega dimainkan langsung secara bersamaan:

\begin{tabular}{|c|c|c|c|c|}
\hline Gimar & $\|: 0 t$ & t & t & $t: \|$ \\
\hline Gendang & $\|: \mathrm{dd}$ & $d d$ & Od & dd : $\|$ \\
\hline Gong & $\|: \quad 0$ & $0 \mathrm{x}$ & 0 & $0 x: \|$ \\
\hline
\end{tabular}

\section{Musik Dewa-dewa}

Introduksi diamainkan secara bersamaan:

\begin{tabular}{l|llll|llll} 
Gimar $\|: 0$ & 0 & 0 & tt & 0 & 0 & 0 & tt $: \|$ \\
Gendang $\|: 0$ & 0 & 0 & $\mathrm{dd}$ & 0 & 0 & 0 & $\mathrm{dd}: \|$ \\
Gong $\|: 0$ & 0 & 0 & $\mathrm{xx}$ & 0 & 0 & 0 & $\mathrm{xx}: \|$ \\
Klentangan: & & & & & & &
\end{tabular}

\begin{tabular}{lllll|llllll}
$\mathrm{Kr}$ & $: 0$ & 0 & 0 & 11 & 0 & 0 & 0 & $11:$ & \\
$\mathrm{Kn}$ & $: 11$ & & $33 \ldots$ & 53 & 22 & 11 & $33 \ldots$ & 53 & $22:$ \\
Mulai lagu: & & & & & & & &
\end{tabular}

\begin{tabular}{lllll|llll} 
Gimar $\quad:$.I .I. & I.I & .I & .I & .I.. & I.I & .I: & \\
Gendang $: j . D$ & D.D & .D & DD & .D & D.D & .D & DD: \\
Gong $\quad: 0$ & $\mathrm{x}$ & 0 & $\mathrm{xx}$ & 0 & $\mathrm{x}$ & 0 & $\mathrm{xx}:$ \\
Klentangan: & & & & & & &
\end{tabular}




\begin{tabular}{l|clll|llll||}
$\mathrm{Kr}$ & $: 0 !$ &.$!$ &. & $! !$ & $0 !$ &.$!$ &. & $! !$ \\
$\mathrm{Kn}$ & $: 55$ & $66 \ldots$ & 65 & 33 & 65 & $66 \ldots$ & 65 & 33 \\
$\mathrm{Kr}$ & $0 !$ &.$!$ &. & $! !$ & $0 !$ &.$!$ &. & $! !$ \\
$\mathrm{Kn}$ & 22 & $33 \ldots$ & 53 & 22 & 11 & $33 \ldots$ & 53 & 22 \\
$\mathrm{Kr}$ & $0 !$ &.$!$ &. & $! !$ & $0 !$ &.$!$ &. & $! !$ \\
$\mathrm{Kn}$ & 11 & $33 \ldots$ & 53 & 22 & 11 & $33 \ldots$ & 53 & $22:$
\end{tabular}

Keterangan :

$I=$ ritmis gimar $\mathrm{D}=$ ritmis gendang

$\mathrm{Kn}=$ pola permaina klentangan dengan tangan

kanan

$\mathrm{kr}=$ pola permainan klentangan dengan tangan kiri

Musik terbentuk berdasarkan suatu susunan dengan bahan nada, melodi, ritme, irama, tempo, harmoni, dinamika, instrumentasi dan lain sebagainya, kemudian disesuaikan dengan tujuan musik tersebut yang dipertunjuk dalam waktu tertentu. Beberapa unsur dan susunan musik yang membentuk musik dewa-dewa adalah sebagai berikut.

Tangga nada atau laras adalah deretan atau susunan titi nada dalam satu oktaf yang memiliki jarak interval tertentu. Hampir seluruh instrumen musik tradisional di Indonesia menggunakan tangga nada atau laras non diatonis (Eli Irawati, 2013: 116). Dalam kasus musik dewa-dewa ini menggunakan tangga nada anhemitonic pentatonic karna titik berat nadanya berada di Do. Klentangan berdasarkan deret nada-nadanya memiliki nada yang berbeda secara tinggi rendahnya.

Permainan klentangan ketika mengiringi belian memiliki tonal nada Do dengan nada dasar Do= Bes. Berikut adalah urutan tangga nada hemitonic pentatonic yang terdapat dalam permainan musik dewa-dewa di guntung Bontang ketika dilangsungkan upacara Pelas Benua tanggal 23 september 2017.

$\begin{array}{llllll}1 & 2 & 3 & 5 & 6 & ! \\ \text { Do } & \text { Re } & \text { Mi } & \text { Sol } & \text { La } & \text { Do }\end{array}$

Nada di atas meupakan urutan nada yang diletakkan pada instrumen klentangan. Dimulai dengan nada Do rendah dari kanan dan berakhir pada nada Do tinggi di kiri. Urutan 
ini memperlihatkan tinggi rendah dan wilayah nada yang ada pada klentangan yaitu semakin ke kiri, nandanya akan semaki tinggi.

Dinamika penyajian musik dewa-dewa ini memiliki dinamika dan tekanan nada yang teratur. Dinamika dari penyajian musik dan irama dengan tekanan nada tertentu akan mempengaruhi psikosifik seseorang, apabila dinamia dan teanannada teratur maka perasaann akan cenderung menjadi teratur juga ( Saragih, 2008: 4). Nada dan irama yang teratur digunakan berulang-ulang dengan menggunakan irama yang tetap. Hal ini membuat belian berinteraksi dengan para dewa dan roh yang dimaksud.

Penyajian tempo musik yang cepat atau lambat pada dasarnya dapat mempengaruhi kondisi dan suasana. Tempo merupakan berfungsi sebagai pengatur jalannya irama suatu musik. Tempo yang dimainkan oleh musik dewa-dewa sebagai pengiring upacara pelas benua ini adalah tempo sedang atau moderato dari dimulainya musik dimainkan hingga berakhirnya penyajian.

Ritme adalah gerakan berturut-turut secara teratur dan dilakukan secara berulang-ulang sehingga menciptakan suatu degupan yang mudah dipahami dan dirasakan karena ritme menghasilkan aksentuasi dan panjang pendek nada Ritme adalah elemen musikal yang berhubungan dengan waktu dan memberikan kesan fungsional yang meliputi tanda-tanda, iringan tari, suasana ritual sampai dengan ide-ide siklus yang mengandunng pola kehidupan sosial penduduknya (Mack, 1995: 7).

Pengantur ritme dalam musik dewa-dewa ini adalah gong, gimar dan gendang.

Gong mempunyai dua titi (pola) permainan yaitu pola dewa semega dan dewa-dewa. pola dewa semega memainkan pukulan yang tetap pola ketukan up beat dan pola dewa-dewaa memainkan pada ketukan on beat. Aksen pukulan pola dewa semega ketukan kedua up beat dan ketukan selanjutnya sebagai dasar. Sedangkan aksen pukulan pola dewa-dewa terdapat pada ketukan pertama on beat selanjutnya sebagai dasar. Sama halnya dengan gimar dan gendang memainkan pola ritme dengan menggunakan birama 4/4 gimar dalam pola dewa semega on beat dimulai diketukan pertama up dan gendang dengan ketukan up beat. Pada pola dewa-dewa gimar dan gendang aksen pukulan terdapat pada ketukan pertama up beat .

Pola ritme yang dimainka oleh ketiga isntrumen tersebut terkesan sederhana dan diulang-ulang. Hal ini agar suasana yang terbentuk dari awal tetap stabil, sehingga belian bisa 
berkomunikasi dengan para roh dan dewa-dewa berjlan lancar. Walaupun pola ritme yang dihasilkan konstan dan berulang-ulang, namun terkaadang terdapat variasi secara spontan pada instrumen ritmis tersebut.

Alur melodi yang bersifat monoton, terdiri hanya satu atau dua nada saja dapat dikatakan sebagai melodi yang memiliki kualitas selestis atau surgawi (Ganap, 2017: 218). Sejalan dengan pernyataan tersebut, Melodi yang dimainkan oleh instrumen klentangan dalam musik dewa-dewa memainkan pola teratur dan berulang membentuk pola ritmis yang saling mengisi dan berkaitan satu sama lain dengan belian (dukun). Pada tingkatan pengulangan atau repetisi yang terbentuk dalam setiap jalinan nada tersebut, pemusik dewa-dewa, belian akan membuat saling keterkaitan dala satu tujuan yang sama yaitu meminta izin kepada dewa dan memberi makan kepada roh agar Erau berjalan lancar.

Berdasarkan efek psikologis, banyak pula pengaruh yang diterima oleh para pelaku dan penikmat bunyi-bunyian dari musik ritual. Efek psikologis yang menonjol diterima oleh para pelaku dan penikmat bunyi-bunyian itu adalah bersumber dari suasana dan karakter dari ungkapann bunyi-bunyian ritual (Senen, 2005: 216). Motif yang sederhana dan diulang-ulang serta ritmis yang monoton dari musik dewa-dewa memunculkan suasana dan karakter magis

Fungsi pada dasarnya merupakan kegunaan sesuatu, sedangkan kedudukan merupakan peranan musik itu dihadirkan. Berkaitan dengan hal ini, musik dewa-dewa adalah satu kesatuan utuh dalam upacara pelas benua, oleh karenanya tidak terlepas dengan unsur pembentuk teks dan konteksnya yang saling berkaitan hingga membentuk fungsi dan kedudukan tertentu demi tujuan musik itu sendiri. Fungsi musik juga merupakan sumbangan aktivitas suatu bagian secara keseluruhan dalam suatu masyarakat yang berarti bahwa musik itu akan menduduki fungsinya apabila masyarakat pendukungnya menganggap bahwa musik merupakan suatu kebutuhan (Brown, 1980: 210).

Musik dewa-dewa yang memiliki dua Pola musik yaitu musik dewa-dewa dan dewa Semega adalah satu kesatuan yang tak bisa di pisahkan dalam berlangsungnya upacara Pelas bеnиa ini, dan juga memiliki peranan untuk menghantarkan jalannya upacara Pelas Benua dari awal hingga akhir sehingga musik dewa-dewa dapat dikatakan sebagai bagian dalam upacara. Musik dewa-dewa yang dimainkan ketika prosesi Upacara Pelas Benua memiliki kedudukan sebagai iringan belian (dukun). Musik dewa-dewa sangat penting kehadirannya serta 
dibutuhkan dalam upacara Pelas Benua sebab upacara tida akan berjalan jika tidak ada musik dewa-dewa. Ada sepuluh fungsi musik yaitu, (1) Musik sebagai Pengungkapkan emosional, (2) Penghayatan estetis, (3) fungsi hiburan, (4) fungsi komunikasi, (5) fungsi perlembagaan, (6)fungsi reaksi jasmani, (7) fungsi ritual, (8) fungsi pengesahan lembaga sosial, (9) fungsi kesinambungan budaya, (10) fungsi pengintergrasian masyarakat (Merriam, 1964). Tetapi pada analisis ini hanya menyesuaikan beberapa fungsi yang berkaitan dengan fungsi musik dalam upacara pelas benua anatara lain sebagai berikut.

Musik dewa-dewa memiliki kekuatan yang merupakan media komuniasi, baik secara vertikal maupun horizontal. Komunikasi horizontal merupakan komunnikasi yang mengarah pada hubungan antara manusia dengan manusia seperti hubungan anatar manusia dengan manusia seperti hubungan sahabat dengan sahabatnya, hubungan anatara ibu dan anak, serta hubungan kemanusiaan lainnya. Satu jenis komunikasi dengan menggunakan musik dewadewa untuk menyampaikan atau tanda-tanda tertentu kepada khalayak. Apabila musik dewadewa sudah dibunyikan maka bunyi ini direspon panca indra yaitu telinga orang yang mendengar umumnya, bunyi musik dewa-dewa yang terdengar dan direspon pendengarnya dengan cara menghampiri ke tempat bunyi-bunyian itu dihadirkan. Musik dewa-dewa selain sebagai benda adat yang dijaga keberadaannya, dipercaya bunyi mengandung pesan yang mampu menghubungkan dan mengumpulkn pribadi-pribadi dalam satu kesatuan ikatan sosial (Lubis, 2013: 38).

Hal ini tercerminkan pada sikap dan perilaku mereka dalam merespon bunyi tersebut. Saat musik dewa-dewa berbunyi dan terdengar warga yang berda di tempat berbeda-beda akan segera mehampiri rombongan Pelas benua saat melewati jalan-jalan menuju tempat yang akan dilakukan upacara pelas benua.

Musik dewa-dewa juga digunakan sebagai komunikasi vertikal atau dalam hal spiritual. Komunikasi vertikal lebih mengacu pada komunikasi yang bersifat dunia supranatural dalam hubungannya dengan kepercayaan terhadap dewa-dewa, tuhan dan para roh. Hal yang dikomunikasikan tersebut berisi pemujaan, persembahan, permohonan, permohonan anugrah, ucapan rasa syukur.

Komunikasi yang terjadi melalui suara yang dihasilkan oleh permainan musik dewadewa dan direspon oleh dewa-dewa dan para roh yang dipercaya akan menjaga dan 
melancarkan segala urusan dan suka cita karena bunyi yang ditimbulan oleh musik dewa-dewa. Musik dewa-dewa akan menjadi sarana bagi belian untuk menyatukan diri dengn keadaan gaib yang dapat menghubungkannya dengan para dewa dan roh, kemudian belian berkomunisa dengan dewa hinggga memberitahu bahwa akan dilaksanakannya Erau.

Sebagai Fungsi,musik dewa-dewa digunakan sebagai sarana penyampaian tujuan ritual dalam upacara pelas benua, menegaskan bahwa musik dewa-dewa yang digunakan masyarakat kutai guntung ini sebagai fungsi ritual. Musik dewa-dewa yang dimainkan menghantarkan belian kepada roh dan dewa-dewa. Salah satu komponen yang cukup penting menjadi keutuhan penyajian dalam memanfaatkan mantra adalah praktik upacara ritual (magis) (Saputera, 2007: 144).

Menurut Frazer, ada istilah sympathetic magic (magis simpatetik) sebagaia adanya hubungan erat antara benda-benda yang sebenarnya secara langsung tidak berhubungan. Magis disini sebagai bentuk ketidak mampuan manusi menghadapi alam semesta, yang dilampiaskan melalui berbagai cara untuk memahami dan mengubah kondisi alam agar berjalan sesuai keinginannya dan segala sesuatu yang bisa disatukan secara mental, maka harus digabungkan dengan dunia luar yang nyata (Frazer, 2009: 124). Musik dewa-dewa yang digunakan dalam upacara pelas benua mengandung hubungan magis simpatetik karena diyakini belian sebagai perantara dapat menghubungkan antara dua alam yang berbeda yaitu roh, dewa-dewa (alam gaib) dan manusia dalam konteks memberikan makan pada roh yang ada di tanah, langit dan laut dan juga sebagai saran meminta izin kepada para dewa dan roh leluhur.

Sebagai Respon Fisik Musik dewa-dewa dalam penyajiannya yang terkait dengan konteks upacara pelas benua ini membentuk respon fisik terhadap aspek gerak/tarian. Tarian ini menyesuaikan dengan bunyi yang terdengaar. Gerak tubuh, langkah kaki, dan ayunan bunyi musik yang dimainkan oleh pemusik. Musik adalah ekspresi seni yang berpangkal pada tubuh karena musik merupakan suatu peredaran atau feadback arus balik dari membunyikan, mendengarkan, dan membunyikan kembali. Memainkan musik atau mendengarkan musik sama artinya berdialog dengan tubuh, gerak tubuh yang dilakukan pendengar ataupun pemain musik tersebut pada dasarnya merupkan akibat pertemuan aktif antara tubuh dengan dunia luar (Shin Nakagawa, 42). Sebagai pengiring upacara, musik dewa-dewa berkedudukan sebagai pengiring belian sebagai sarana menuju para roh dan para dewa, selain itu juga musik dewa- 
dewa meberikan respon gerak menari sebgai rasa kegembiraan bahwa esok harinya akan dilaksanakan upacara Erau. Bunyi-bunyian tersebut dapat mendukung suasana upacara yang magis, religius, dan penuh suka cita.

\section{Kesimpulan}

Seperti suku kutai yang lainnya, Kutai Guntunng juga memiliki adat istiadat dan kearifan lokal yang sedikit berbeda dalam aturan menjalankan aturan adat. Perbedaan ini terlihat dalam upacara Pelas benua yang menjadi keunikan dalam rangkaian upacara Erau pelas benua. Pelas benua merupakan upacara sebelum dilaksanakannya Erau, pelas benua merupakan ritual yang tidak boleh dilewatkan, pelas benua bertujuan meminta izin dan memohon perlindungan kepada para dewa, dewa semega dan leluhur. Seluruh rangkaian kegiatan yang terlaksana dalam upacara pelas benua tidak lepas dari sesaji yang bertujuan memberi makan kepada leluhur dan makhluk tidak kelihatan seabagai simbol penghormatan dan juga meminta perlindungan dan izin kepada leluhur dan para dewa. Upacara pelas benua merupakan tahapan menuju Erau melalu media penghantar mantra dan musik dewa-dewa. Kegiatan pelas benua ini dilaksanakan dengan berkeliling ke empat penjuru mata angin dengan diiringi musik dewa dan seorang dukun yang merupakan penghubung antara para dewa dan juga roh leluhur dan roh yang tidak kelihatan.

Musik dan mantra yang hadir dalam bentuk alunan yang khas dan sederhana ini diulang-ulang, yang dipercayai memiliki kekuatan yang besar pada saat upacara berlangsung. Hal ini karena fungsi musik sebagai penghubung antara dukun, para roh dan dewa saling bekomunikasi serta hubungan magis yang tercipta dipercaya mampu menghubungkan antara dukun dan para roh. Dengan demikian, jika dilihat keseluruhan prosesi dalam upacara pelas benua ini, sangat memegang teguh kepercayaan terhadap leluhur, para dewa dan sang pencipta.

\section{Daftar Pustaka}


Haryanto. 2015. Musik Suku Dayak: Sebuah Catatan Perjalanan di Pedaalaman Kalimantan. Yogtakarta: Badan Penerbit ISI Yogayakarta

Irawati, Eli. 2013.Eksistensi Tingkilan Kutai: Suatu Tinjauan Etnomusikologis. Y Yogyakarta: Kaukaba Dipantara.

Prier SJ, Karl-Edmund. 1996. Ilmu Bentuk Musik. Yogyakarta: Pusat Musik $\quad$ Liturgi.

Senen, I Wayan. 2015. Bunyi-Bunyian Ritual dalam Upacara Keagamaan Hindu di Bali. Yogyakarta: Balai Penerbit Institut Seni Indonesia.

Soedarsonono, R. M. 2002. Seni Pertunjukan Indonesia di Era Globalisasi. $\quad$ Yogyakarta: Gajah Mada University Press.

\section{Sumber Lain}

https://kbbi.web.id/dewa diakses pada tanggal 15 januari 2018

\section{Narasumber}

Abdul Hamid, 65 tahun, Dewan Pembina Adat Kutai Bontang, Pegawaii Negri Sipil, Bontang, Kalimantan Timur.

Juhar Burhan, 54 tahun, Dewan Pembina Musik Dewa-Dewa Adat Kutai Bontang, Pegawai Negri Sipil, Bontanng, Kalimantan Timur

M. Daud Bin Ahmad, 98 tahun, Ketua adat Kutai Bontang, Wirausaha, Bontang, Kalimantan Timur 